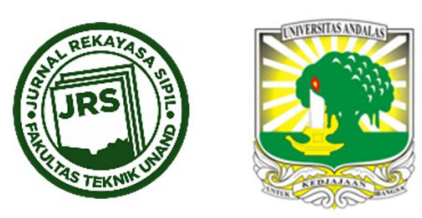

\title{
NUMERICAL MODELLING OF GLASS FIBRE REINFORCED POLYMER (GFRP) TUBE SUBJECTED TO TORSION
}

\author{
AGUSRIL SYAMSIR ${ }^{1,2 *}$, AMIRA BINTI MOHD HAFIZ ${ }^{2}$ \\ ${ }^{1}$ Institute of Energy Infrastructure (IEI), Universiti Tenaga Nasional, Malaysia \\ ${ }^{2}$ Civil Engineering Department, College of Engineering, Universiti Tenaga Nasional, Malaysia \\ *Corresponding author: $ه$ agusril@uniten.edu.my
}

Submitted : 11 July 2020. Accepted: 28 July 2021

\section{ABSTRAK}

Glass Fibre Reinforced Polymer (GFRP) tubes have been used widely as cross arm of electric transmission towers to replaced old wooden cross arms. Cross arm is a part of transmission tower which is required to support conductors or electrical cables. The cross arm is produced by assembling three or four GFRP tubes using steel connector to connect all three or four members to the body of transmission tower. Due to nature of assembly of these GFRP tubes, it will induce torsional force to the individual GFRP tubes of cross arm. Although numerous studies have been conducted on the torsional behavior of circular concrete filled FRP tubes, none had performed on the behavior of square GFRP tubes numerically. Thus, the work proposed to study the behavior of square GFRP tubes subjected to torsional load. In this paper, the performance of glass fiber-reinforced polymer (GFRP) tubes under statically torsional loads was studied numerically. The specimens' ultimate twisting angle and strain were studied through experimental work for validation of the numerical model. Explicit solver of ANSYS was chosen and simulation results matched experiment results well with $4 \%$ different of strains between experimental and numerical model. Parametric study has been done to six GFRP tube models with various fibre orientation while maintain the same number of layers GFRP in the tube. It is concluded that model 4 shown the highest ultimate strains as well as twisting angle while model 3 has the lowest ultimate strains and twisting angle. The presence of fiber orientation of $90^{\circ}$ in model 4 has contributed to the torsional capacity of the tubes.

Kata kunci : numerical model torsional force, GFRP

\section{INTRODUCTION}

Glass Fibre Reinforced Polymer (GFRP) tubes have been used recently as cross arm of electric transmission towers. Characteristic as well as mechanical properties of various GFRP cross arms have been investigated by Nadhirah et. al. (2017) that reveal that different brand of cross arm produced different properties even though it has the same dimensions. Many factors that causing failure of GFRP tubes have been identified by previous researcher such as due to environment effect such as temperature, humidity, as well as due to creep effect on 
the tubes (Beddu et al., 2018; Syamsir et al., 2019, 2018). The cross arms during operation will be imposed combination of forces such vertical, horizontals and longitudinal specially during broken wire conditions. This broken wire condition will induce torsional forces to the cross arms (Mohamad, Beddu, et al., 2019). Failure of GFRP due to torsion will cause resin crushing and fibre rupture especially at the edges of the tubes, where the failure mechanism can be assessed by using various failure criterion such as Tsai Hill and Tsai Wu criterion (Syamsir et al., 2012). Although numerous studies have been conducted on the torsional behavior of circular concrete filled FRP tubes, none had performed on the behavior of square GFRP tubes numerically. Thus, the work proposed to study the behavior of GFRP tubes subjected to torsional load.

According to previous research on numerical modelling of GFRP tubes, it was revealed that ANSYS is suitable to be used to model and analyse the GFRP tubes. In GFRP modelling it is required to determine thickness and also mechanical properties of each layer of fibers and resin so call lamina that available in ANSYS Composite Prepost (ACP) module (Mohamad, Syamsir, et al., 2019). In this study a numerical modelling will be performed for GFRP tubes which is subjected to torsional forces. Validation on numerical model shall be performed by comparing the strains which are obtained from numerical model with experimental work at the same location.

\section{NUMERICAL AND EXPERIMENTAL PROGRAM}

\subsection{Material Properti}

The hollow pultruded GFRP square tubes (125 $\mathrm{mm} \times 125 \mathrm{~mm} \times 6.5 \mathrm{~mm}$ ) used in this study are made up of vinyl ester resin and E-glass fibre reinforcement. The tubes consisted of nine plies of $\left[0^{\circ} /+45^{\circ} / 0^{\circ} /-45^{\circ} / 0^{\circ} /-45^{\circ} / 0^{\circ} /+45^{\circ} / 0^{\circ}\right]$ E-glass fibre manufactured using pultrusion process by Wagner's Composite Fibre Technologies (WCFT), Australia. Mechanical properties of Wagner GFRP tubes and steel lever arm is given in Table 1.

Table 1. Properties of GFRP tube and steel level arm

\begin{tabular}{lll}
\hline Material Propertis & GFRP tube & $\begin{array}{l}\text { Steel moment } \\
\text { arm }\end{array}$ \\
\hline Density $(\mathrm{kg} / \mathrm{m} 3)$ & 1900 & 7850 \\
\hline Young modulus in X, Ex (MPa) & 10000 & 200000 \\
\hline Young modulus in Y, Ey (MPa) & 1000 & 200000 \\
\hline Young modulus in Z, Ez $(\mathrm{MPa})$ & 500 & 200000 \\
\hline Shear modulus, Gxy=Gxz=Gyz $(\mathrm{MPa})$ & 1500 & 76900 \\
\hline Poisson's ratio, vxy=vyz=vyz & 0.15 & 0.3 \\
\hline
\end{tabular}

\subsection{Numerical modelling procedure}

3D models are shown in Figure 1 (a) and (b) for GFRP tubes and assembly model of tube and steel lever arm, respectively. These models were then transferred to ANSYS program to develop the three-dimensional finite element model in order to perform the required linear analysis. This includes defining the material properties, modelling the (GFRP) laminates with fibers' directions, meshing, supports and loads acting on the tube. The simulation was then performed by using the ANSYS Composite Prepost (ACP) module. The materials properties for both tubes and steel lever arm were taken Table 1. A new glass unidirectional fibers material was created and all orthotropic properties were keyed in including orthotropic elasticity, orthotropic stress limits and orthotropic strain limits. 


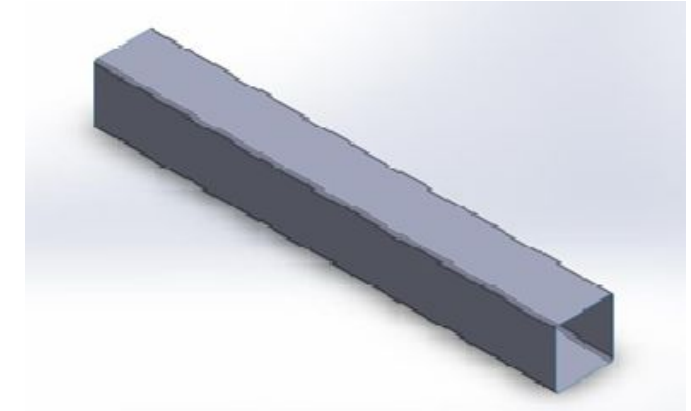

(a) Model size $125 \mathrm{~mm}$ x $125 \mathrm{~mm}$ x $1000 \mathrm{~mm}$

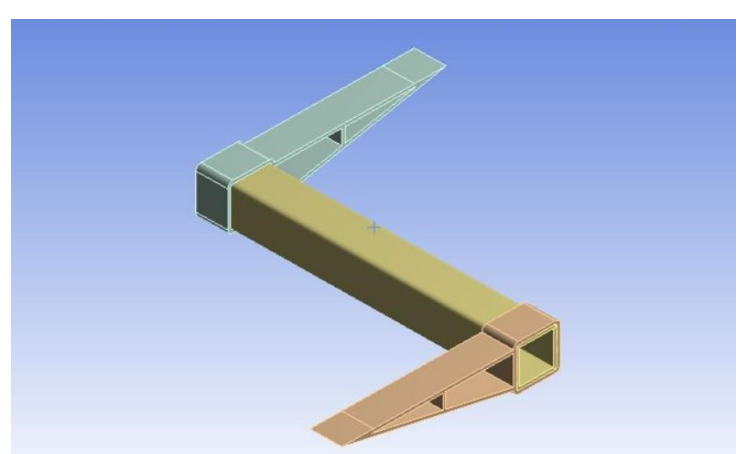

(b) Assembly model

Figure 1. 3D geometrical modelling of GFRP tube (a) and steel lever arm (b)

After defining all materials properties, the 3D geometrical model of the composite members was imported. Then it was meshed with a mesh size of $20 \mathrm{~mm}$ which was investigated and determined to maintain a balance between computational time and results accuracy as shown in Figure 2 (a) and (b).

Quadrilateral elements were used as much as possible and the aspect ratio was inspected and was found that almost all elements had a ratio of 1 or very close to it. After that, the plies were created and stacked up based on the configuration and fibers direction needed with the fabric thickness desired. The typical configuration was set as Muttashar et al. (2017) mentioned, in which they used the same hollow sections from Wagner's Composite Fibre Technologies (WCFT), Australia, that were modelled in this paper. The stack up consisted of 9 plies of GFRP with a thickness of $0.7 \mathrm{~mm}$ per ply with a total thickness of $6.3 \mathrm{~mm}$, and fiber directions $\left(0^{\circ} /+45^{\circ} / 0^{\circ} /-45^{\circ} / 0^{\circ} /-45^{\circ} / 0^{\circ} /+45^{\circ} / 0^{\circ}\right)$ in which $0^{\circ}$ direction represents the member's longitudinal direction. In this simulation steel lever arm was connected to GFRP tube and vertical forces with the same value were applied to the tip of the lever arm in order to induce torsional force to the tube.

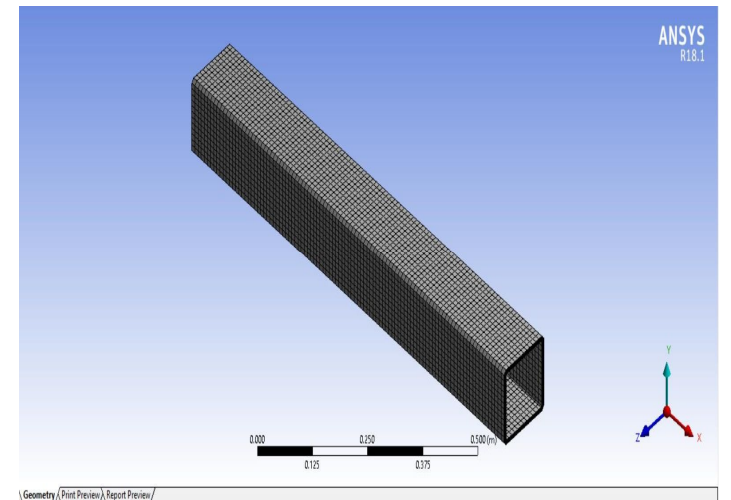

(a) Meshing of GFRP tubes

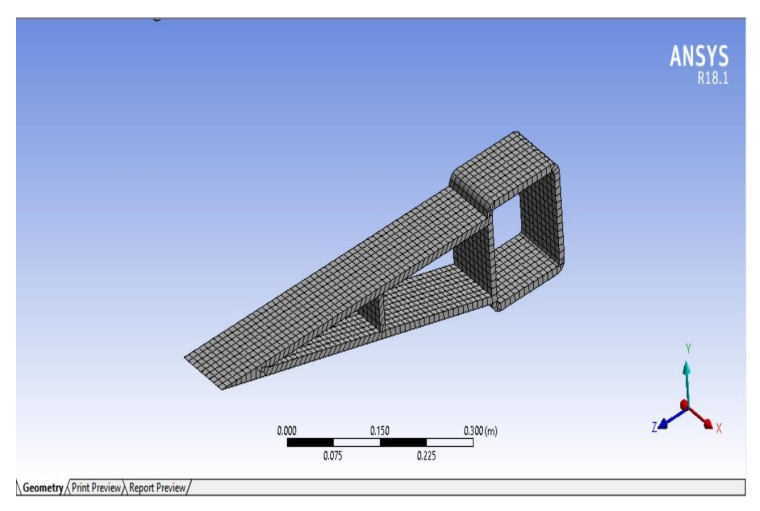

(b) Meshing of steel lever arm

Figure 2. 3D geometrical modelling of GFRP tube (a) and steel lever arm (b)

Validation of numerical model will be performed by comparing the ultimate torsional strain obtained from this model with experimental results. Parametric study will be done later in order to investigate the effect of fiber orientation on the ultimate strain at the 
middle of the tube and also the twisting angle which is measured by using two inclinometers placed above the lever arms.

\subsection{Test setup and experimental procedure}

The experimental work is shown in Figure 3. GFRP tubes were tested under pure torsional loading up to the ultimate torque. The ends of the tube were supported a free-rotating steel cylinder that will allow the supports to rotate freely. These supports were connected to steel moment arm and the load was applied to the tip of lever arm by using a spreader beam which is diagonally laid down resting on the arms. The torsional arm extended $615 \mathrm{~mm}$ from the central axis of the tube. The advantage of this setup is the middle part of the specimen is subjected to pure torsion by applying a single vertical load from top. The specimen is placed over the two steel roller bearings leaving gap from the end of the beam. The load was applied constantly until the failure occurred. Before the test proceed, it is required to ensure that the inclinometer set to zero to prevent parallax error. The process was started with twisting the specimen and increased the angle of twist until the torsional failure of specimen occurred. All the experimental data were recorded in such as torsional moment and angle of twist. Torsional test set up can be observed in Figure 3 while the actual torsion test rig is shown in Figure 4.

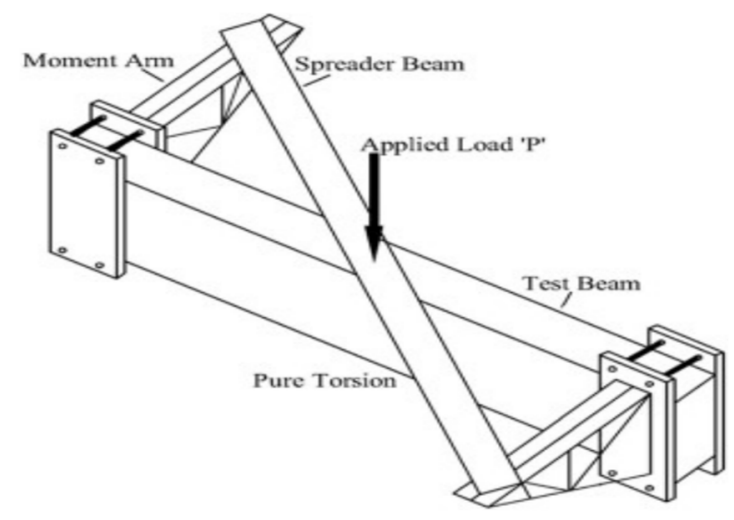

Figure 3. Torsional test set up (Chalioris, 2008)

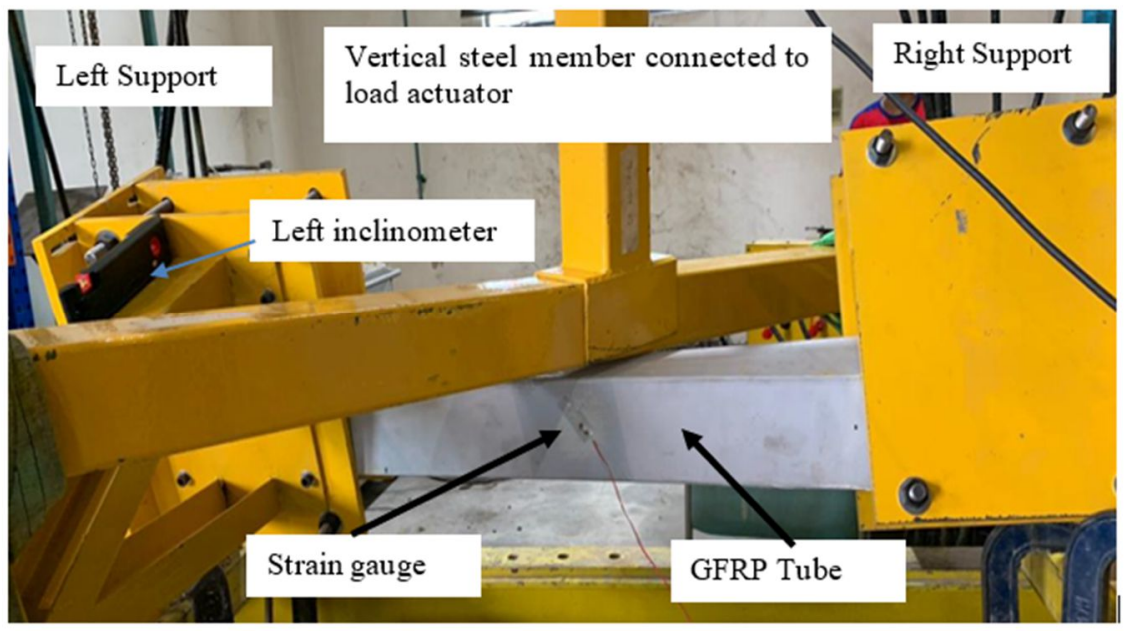

Figure 4. Experimental work on GFRP tubes at UNITEN laboratory 
In Figure 4 it can be observed that condition of tubes after failure. Location of strain gauges and inclinometer also can be seen here. In this experiment two inclinometers were used to record the twisting angle of the tubes at supports by attaching the inclinometer above the left and right steel moment arms.

\section{RESULTS AND DISCUSSION}

\subsection{Model validation}

Results from experimental work such as torsional moment, angle of twist, and strain were shown in Table 2. The validation has been done by comparing the angle of twist and strains obtained from experimental work with the strains obtained from numerical model at the same location. From this table, it can be observed that the differences between strains obtained from experimental and numerical results are less than $5 \%$ which is considered acceptable (Lee et al., 2019). The difference of twisting angle between experimental and numerical work is $23 \%$, this may be due to the error data recording. In this study the inclinometer was placed on the left support, while during the test it was found there is a gap between the tubes and the support after testing. This maybe cause the error for the twisting angle data that had been captured. However, the validation using strains comparison is acceptable for this study.

Table 2. Strains at the middle of tubes

\begin{tabular}{lllllllll}
\hline No. & $\begin{array}{l}\text { Load } \\
(\mathbf{k N})\end{array}$ & $\begin{array}{l}\text { Torsional } \\
\text { Moment }\end{array}$ & \multicolumn{2}{c}{$\begin{array}{c}\text { Angle of Twist } \\
\text { (in degree) }\end{array}$} & $\begin{array}{l}\% \\
\text { Diff }\end{array}$ & Strain $(\boldsymbol{\mu} \varepsilon)$ & $\begin{array}{l}\% \\
\text { Diff }\end{array}$ \\
\hline & & & Experiment & ANSYS & Experiment & ANSYS \\
\hline 1 & 0 & 0 & 0 & - & - & 0 & 0 & 0 \\
\hline 2 & 0.257 & 0.158 & 5.30 & - & - & 319 & 325 & 1.9 \\
\hline 3 & 1.296 & 0.797 & 10.50 & - & - & 956 & 998 & 4 \\
\hline 4 & 2.224 & 1.368 & 12.20 & 15 & $23 \%$ & 1167 & 1196 & 2.5 \\
\hline
\end{tabular}

\subsection{Effect of fiber orientation on ultimate strain of GFRP tubes}

The result of ultimate strain values are stated in Table 3. From this table it can be observed that model 4 has the highest torsional strains due to the presence of fibre $90^{\circ}$ orientation while the lowest is model 3 which has $0^{\circ}$ fibre orientation. Fiber $45^{\circ}$ in model 5 and 6 contribute more torsional resistance as compared to model 2. The combination of $+45^{\circ}$ and $-45^{\circ}$ fiber in model 6 has increased the strain by $1.5 \%$ as compared to model 5 which use $+45^{\circ}$ only. This finding is in line with the previous research on the use of fiber for retrofitting of RC beam subjected to torsion by Alabdulhady dan Sneed (2019). He found that fiber $90^{\circ}$ has better contribution to torsional resistance as compared to $45^{\circ}$ fiber direction.

Strains at the middle of tubes can be observed in Figure 5, and Figure 6 for model 1, and 2, respectively. The ultimate strains in numerical simulations were taken at the middle of the tubes to be suited with the location of strain gauges in the experimental work.

Table 3. Value of fibre orientation of GFRP tube

\begin{tabular}{lll}
\hline Model No. & Fiber orientation & Ultimate Strain $(\mu \varepsilon)$ \\
\hline 1 & $0 / 45 / 0 /-45 / 0 /-45 / 0 /+45 / 0$ & 1196 \\
\hline 2 & $0 / 90 / 45 / 90 / 0 / 90 / 45 / 90 / 0$ & 1304 \\
\hline 3 & $0 / 0 / 0 / 0 / 0 / 0 / 0 / 0 / 0 / 0$ & 1050 \\
\hline 4 & $90 / 90 / 90 / 90 / 90 / 90 / 90 / 90 / 90$ & 2317 \\
\hline
\end{tabular}




\begin{tabular}{lll}
\hline Model No. & Fiber orientation & Ultimate Strain $(\mu \varepsilon)$ \\
\hline 5 & $45 / 45 / 45 / 45 / 45 / 45 / 45 / 45 / 45$ & 1906 \\
\hline 6 & $45 /-45 / 45 /-45 / 45 /-45 / 45 /-$ & 1936 \\
& $45 / 45$ & \\
\hline
\end{tabular}

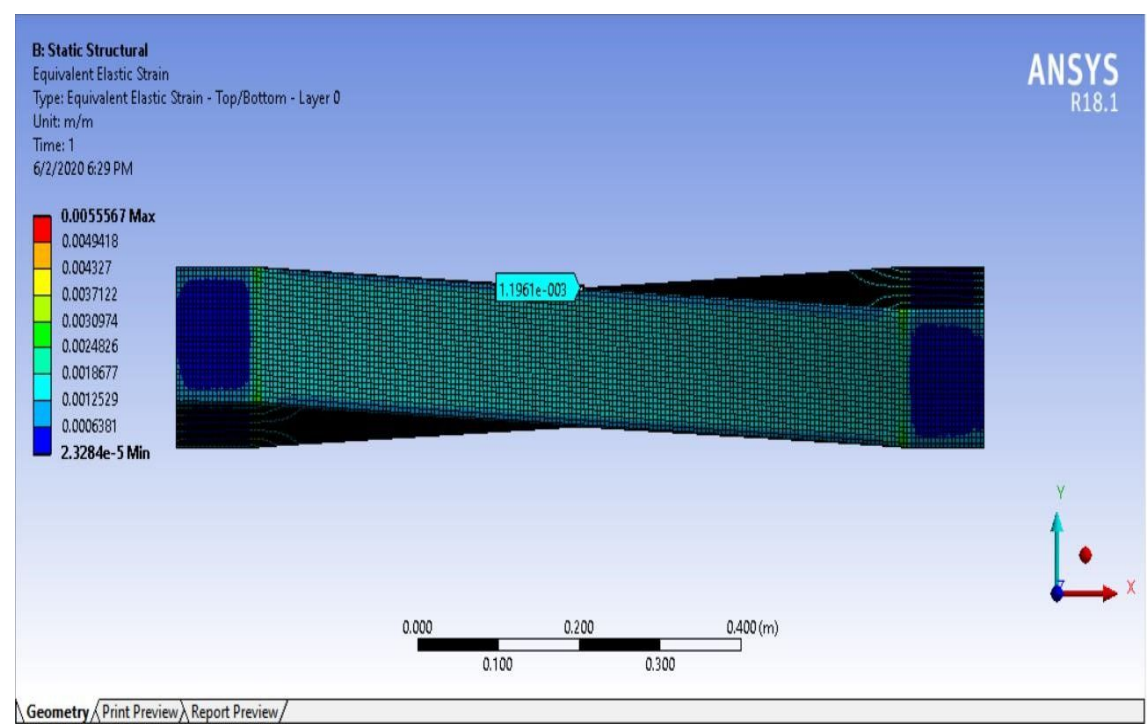

Figure 5. Ultimate strain value for model 1

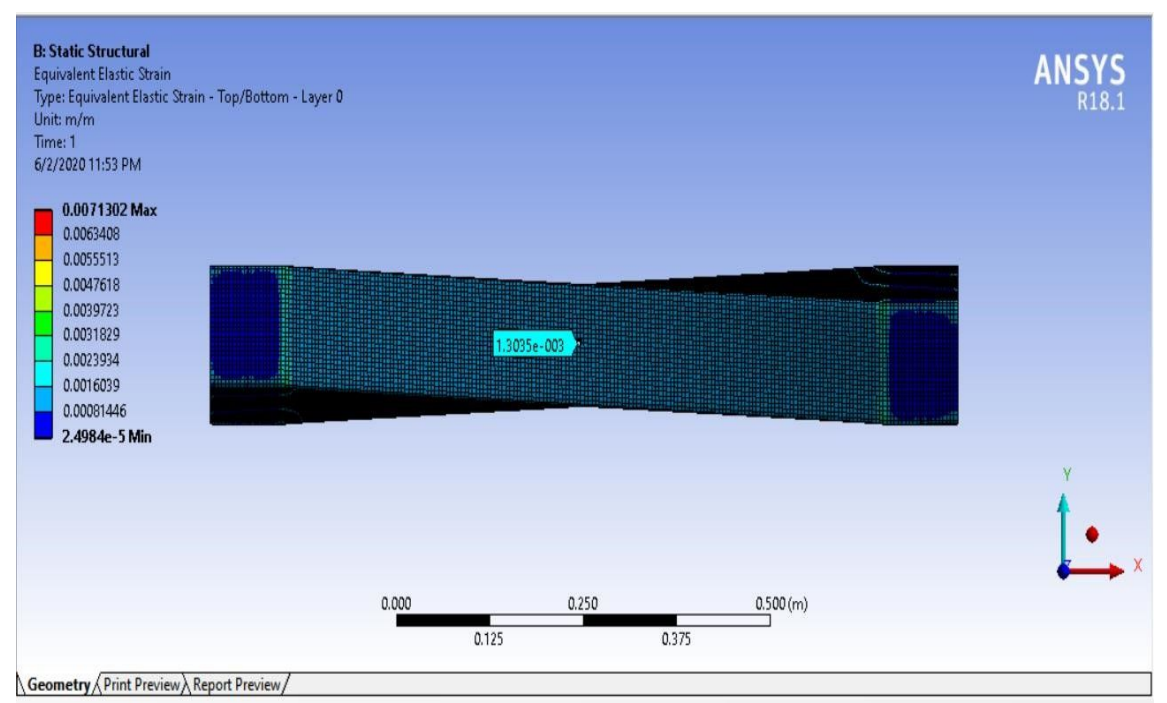

Figure 6. Ultimate strain value for model 2

\subsection{Effect of fiber orientation on Twisting angle}

The result of twisting angle value is stated in Table 4. Twisting angle is calculated from the result of directional deformation in $\mathrm{x}$-axis and $\mathrm{y}$-axis by using equation (1) as shown below. Example of simulation in order to get the value of directional deformation is illustrated in Figure 7 and Figure 8. 
Table 4. Twisting angle of GFRP tubes for various fibre orientation

\begin{tabular}{clcccc}
\hline $\begin{array}{c}\text { Model } \\
\text { No. }\end{array}$ & \multicolumn{1}{c}{ Fiber orientation } & $\begin{array}{c}\text { Deformation } \\
\text { on x-axis } \\
\left(\mathrm{x10}^{-6}\right)\end{array}$ & $\begin{array}{c}\text { Deformation } \\
\text { on y-axis } \\
\left(\mathrm{x10}^{-6}\right)\end{array}$ & $\begin{array}{c}\text { Twisting } \\
\text { angle } \\
(\mathrm{o})\end{array}$ & $\begin{array}{c}\text { Percentage } \\
\text { difference } \\
(\%)\end{array}$ \\
\hline 1 & $0 / 45 / 0 /-45 / 0 /-45 / 0 / 445 / 0$ & 1.314 & 0.358 & 15 & \\
\hline 2 & $0 / 90 / 45 / 90 / 0 / 90 / 45 / 90 / 0$ & 1.449 & 0.539 & 20.4 & 59 \\
\hline 3 & $0 / 0 / 0 / 0 / 0 / 0 / 0 / 0 / 0 / 0$ & 1.276 & 0.137 & 6.16 & 2 \\
\hline 4 & $90 / 90 / 90 / 90 / 90 / 90 / 90 / 90 / 90$ & 1.167 & 2.762 & 67.09 & 36 \\
\hline 5 & $45 / 45 / 45 / 45 / 45 / 45 / 45 / 45 / 45$ & 1.254 & 1.016 & 39.02 & 160 \\
\hline 6 & $\begin{array}{l}45 /-45 / 45 /-45 / 45 /-45 / 45 /- \\
45 / 45\end{array}$ & 1.163 & 0.991 & 40.43 & 347 \\
\hline
\end{tabular}

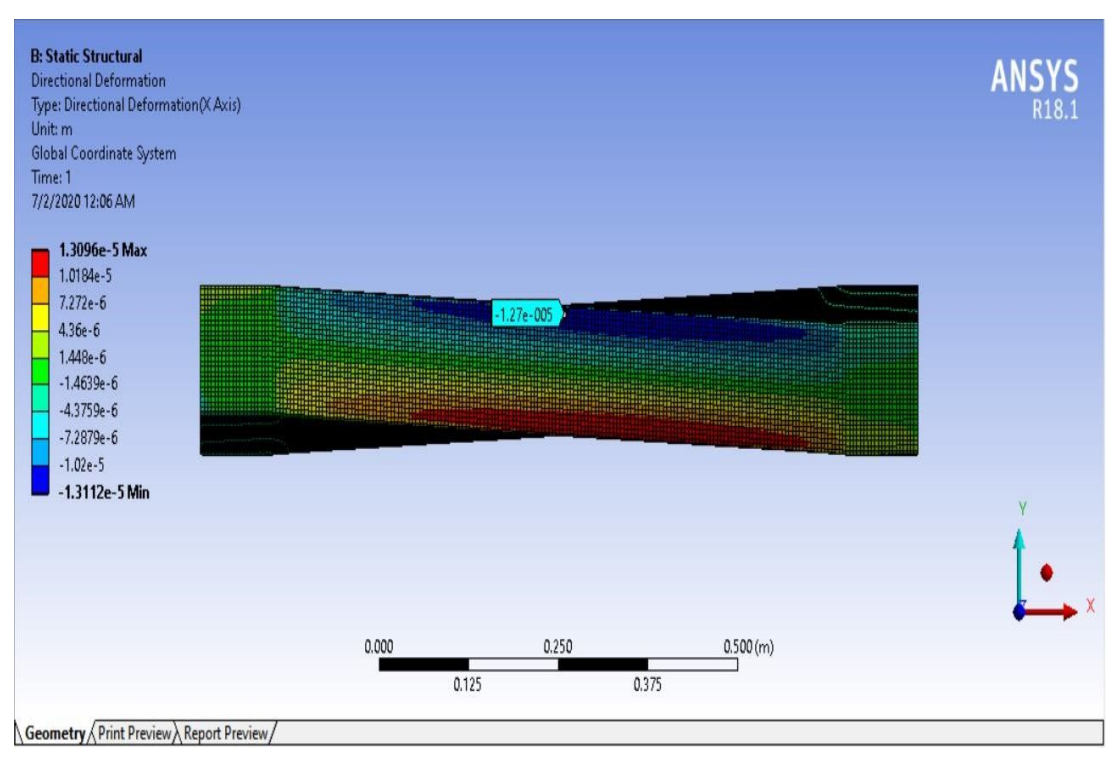

Figure 7. Directional deformation on $\mathrm{x}$-axis of model no.3

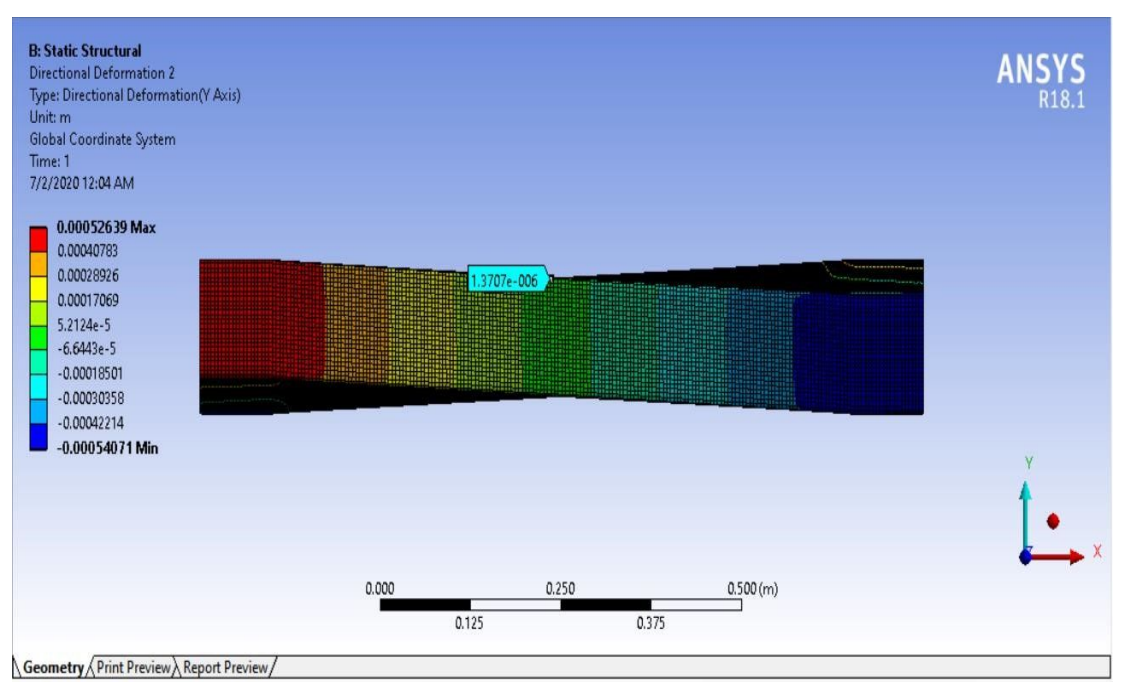

Figure 8. Directional deformation on y-axis of model no.3 
Calculation for twisting angle are based on deformation of $\mathrm{x}$-axis and $\mathrm{y}$-axis. The formula is shown below:

$$
\begin{aligned}
& \tan \emptyset=\frac{y}{x} \\
& \text { Where, } \\
& \varnothing=\text { twisting angle } \\
& \mathrm{y}=\text { deformation of } \mathrm{y} \text {-axis } \\
& \mathrm{x}=\text { deformation of } \mathrm{x} \text {-axis }
\end{aligned}
$$

It can be observed from Table 4 that model no. 4 has the highest twisting, that reveal that this model is fail after reaching twisting angle $67.09^{\circ}$. This result is in line with result in Table 3 which is showing this model has the highest ultimate strains. Model 3 which has $0^{\circ}$ fiber orientations show the lowest twisting angle of $6.16^{\circ}$. It means that this model has failed due to the lowest load as compared to the other models. It also can be observed in Table 3 that this model no. 3 has the lowest ultimate strain.

\section{CONCLUSIONS}

This paper discussed on numerical modelling of GFRP tube subjected to torsional force. The main conclusions from this study are summarized below:

- Validation has been performed for numerical model which has different of $4 \%$ between numerical model and experimental test. It can be considered acceptable as less than $5 \%$.

- Model 4 shows the best performance that produced the highest strains of 2317 micro strains while model 3 has the lowest strains of 1050 micro strain.

- Model 4 also show the best performance that produced the highest twisting angle before fail of 67.090 while model 3 has the lowest twisting angle of 6.16o.

- It can be concluded that the fiber orientation of 900 in model 4 has the best performance among the models which shown the highest ultimate strains as well as twisting angle that prove that this fiber orientation was able to supported the higher load as compared to the other model.

\section{ACKNOWLEDGEMENT}

The authors acknowledge Tenaga Nasional Berhad (TNB), UNITEN R\&D, and Institute of Energy Infrastructure (IEI) for the lab facilities and financial support (TNB Seeding Fund: U-TS-RD-19-03). Special thanks to Goh Lik Meng for helping on conducting torsional test at UNITEN laboratory and also to those who are contributed to this project directly or indirectly.

\section{REFERENCES}

Alabdulhady, M. Y., \& Sneed, L. H. (2019). Torsional strengthening of reinforced concrete beams with externally bonded composites: A state of the art review. Construction and Building Materials, $205,148-163$.

Beddu, S., Syamsir, A., Ishak, Z. A. M., Yusof, Z. M., Hudi, N. S., \& Nabihah, S. (2018). Creep behavior of glass fibre reinforced polymer structures in crossarms transmission line towers. AIP Conference Proceedings, 2031(1), 20039.

Chalioris, C. E. (2008). Torsional strengthening of rectangular and flanged beams using carbon fibrereinforced-polymers-Experimental study. Construction and Building Materials, 22(1), 21-29.

Lee, H., Jang, H., \& Chung, W. (2019). Effect of Recycled Concrete on the Flexural Behavior of Concrete-Filled FRP Tubes. International Journal of Concrete Structures and Materials, 13(1), 1-10. 
Mohamad, D., Beddu, S., Kamal, N. L., Zahari, N. M., \& Zainoodin, M. M. (2019). An examination on torsional loading and environmental effect on glass fibre reinforced polymer cross arm in transmission line tower.

Mohamad, D., Syamsir, A., Beddu, S., Abas, A., Ng, F. C., Razali, M. F., \& Seman, S. (2019). Numerical study of composite fiberglass cross arms under statics loading and improvement with sleeve installation. IOP Conference Series: Materials Science and Engineering, 530(1), 12027.

Muttashar, M., Manalo, A., Karunasena, W., \& Lokuge, W. (2017). Flexural behaviour of multi-celled GFRP composite beams with concrete infill: Experiment and theoretical analysis. Composite Structures, 159, 21-33.

Nadhirah, A., Beddu, S., Mohamad, D., Zainoodin, M., Nabihah, S., Zahari, N. M., Itam, Z., Mansor, M. H., Kamal, N. L. M., \& Alam, M. A. (2017). Properties of fiberglass crossarm in transmission tower-a review. International Journal of Applied Engineering Research, 12(24), 15228-15233.

Syamsir, A., Ishak, Z. A. M., Yusof, Z. M., Salwi, N., \& Nadhirah, A. (2018). Durability control of UV radiation in glass fiber reinforced polymer (GFRP)-A review. AIP Conference Proceedings, $2031(1), 20033$.

Syamsir, A., Mohamad, D., Beddu, S., Itam, Z., \& Sadon, S. N. (2019). An examination on durability and degradation of glass fiber reinforced polymer structures. Test Eng. Manage, 81, 3379-3388.

Syamsir, A., Nor, N. M., \& Zhao, Z. J. (2012). Failure analysis of Carbon Fiber Reinforced Polymer (CFRP) bridge using composite material failure theories. Advanced Materials Research, 488, 525-529. 